\title{
EXPLORING THE DEVELOPMENT OF AN ORGANISATIONAL CULTURE OF CONTROL AND DEPENDENCY FROM A SYSTEMS PSYCHODYNAMIC PERSPECTIVE
}

\section{Author:}

René van Eeden ${ }^{1}$

\section{Affiliation:}

${ }^{1}$ Department of

Psychology, University of

South Africa, South Africa

\section{Correspondence to:}

René van Eeden

email:

veeder@unisa.ac.za

Postal address:

PO Box 392, Pretoria 0003, South Africa

\section{Keywords:}

organisational behaviour; organisational dynamics; group relations theory; open systems theory; psychoanalysis

\section{Dates:}

Received: 26 Aug. 2009 Accepted: 02 Mar. 2010 Published: 12 May 2010

How to cite this article: Van Eeden, R. (2010). Exploring the development of an organisational culture of control and dependency from a systems psychodynamic perspective. SA Journal of Industrial Psychology/SA Tydskrif vir Bedryfsielkunde, 36(1), Art. \#854, 11 pages. DOI: 10.4102/sajip.v36i1. 854

This article is available at: http://www.sajip.co.za

C 2010 . The Authors. Licensee: OpenJournals Publishing. This work is licensed under the Creative Commons Attribution License.

\section{ABSTRACT}

Orientation: Globalisation and accelerating rates of change characterise the work environment.

Research purpose: The aim of this research was to study the impact of the change process at a plant of a South African production company.

Motivations for the study: Problems were experienced in terms of production and a need for transformation at different levels was expressed. Co-dependence in the environment necessitated exploration of intra-organisational dynamics.

Research design, approach and method: The study focused on the management team at a specific plant, but by applying the systems psychodynamic perspective it was possible to also explore the mutual effect of relationships with other systems in the organisation, the company as a whole and the environment. Respondents included the directors of manufacturing and of human resources, the general manager, an 11-member management team and staff representatives. Semi-structured one-to-one interviews, group interviews and a group consultation session were held.

Main findings: Hypotheses were formulated regarding the change experienced in the company, the overemphasis of control in the various systems, efforts to move from dependency to interdependence, personal authority as a requirement for interdependent functioning and problems with interrelatedness.

Practical/managerial implications: The study illustrates the application of the systems psychodynamic approach in exploring the interaction between and mutual influence of various organisational systems, especially in times of change.

Contribution/value add: At a broader level, the study contributes to the understanding of the application of the theory as well as suggesting the use of a methodology. Recommendations for an intervention of this nature were also made.

\section{INTRODUCTION}

Accelerating rates of change in the work environment are affecting various organisational domains, necessitating transformation in all the related systems of organisations - that is, change in organisational cultures (Gordon-Brown \& Bendixen, 2002; Horwitz, Kamoche \& Chew, 2002; Rosenzweig, 1998; Van der Colff, 2003). The present study focused on change and its effect at a plant of a South African production company. The context was one of change, both at an operational level and in terms of personnel needs and the co-dependence in the environment suggested the need for a systemic approach. This article considers the impact of the change process throughout the organisation by providing a broad perspective on the management team's reaction to the need for change and the process of change. Not only were the relationships in the group explored, but also relationships of the group with other systems in the organisation, with the company as a whole, with systems in the environment and even with society.

Group processes refer to the manifest aspects of a group, including maintenance behaviours (communication, participation, etc.) and task behaviours (problem formulations, the development of solutions, etc.). Group dynamics, however, refers to the latent aspects of a group that influence conscious processes and the group's manifest behaviours (Cilliers \& Koortzen, 1997). It is considered essential that these latent aspects be studied when dealing with an organisation experiencing change (Krantz, 2001). In order to do this, a systems psychodynamic approach was adopted in the present study. Firstly, this approach provides for the exploration of issues of authority, power and leadership that are central to the dynamics in a group and are at the core of transformation. Secondly, this approach also allows for the interaction between the structural features of the organisation and its members, which stimulates patterns of individual and group dynamic processes resulting in the organisation's culture (Miller, 1993; Miller \& Rice 1967, 1975, 1990). The systems psychodynamic perspective is based on the theory and concepts of psychoanalysis, group relations and open systems (Gould, 2001). What follows is an exploration of this approach based on theory and research. This served as the basis for the research design and also provided an explanatory framework for the present study.

The psychodynamics of the group implies a psychoanalytic perspective on group experiences as well as on organisational life. Hidden aspects of the individual's mental life influence his or her conscious processes. A similar dynamic can be proposed for the unconscious aspects of the group and the group's manifest behaviours (Gould, 2001). A distinction can be made between objective anxiety resulting from external sources of danger and neurotic anxiety resulting from subjective and frequently unconscious feelings. Melanie Klein's $(1959,1985)$ theory of development explains how ego defences are used to turn an internal threat into an external one. The concepts of the paranoid-schizoid position (involving the defence mechanisms of splitting, projection and projective identification) and the depressive position 
(accompanied by guilt and despair when facing reality) are central to her theory. According to Klein $(1959,1985)$, adults can regress to the infantile mechanisms characteristic of these positions.

Bion $(1961,1975)$ explains how these phenomena manifest not only as individual but also as group phenomena, thus forming the basis for group relations theory. The concept of basic assumption groups is used to explain the manifestation of these defences (Bion, 1961, 1975; De Board, 1978; Kets de Vries \& Miller, 1984; Rioch, 1970, 1975). The manifest aspects of a group (the work group) refer to behaviours that are geared towards rational task performance, whereas the latent aspects (basic assumption group) refer to those behaviours that are geared towards emotional needs and anxieties - that is, towards the group's survival. The basic assumption positions initially identified by Bion are dependency, fight/flight and pairing, while 'me-ness' (Turquet, 1974) and 'we-ness' (Lawrence, Bain \& Gould, 1996) were also acknowledged later. The rational working of the group is affected by its members' (often irrational) emotions. Once the group recognises and deals with this fact, members can focus on the primary task of the group (although groups may regress temporarily after having made progress). Central to all basic assumption groups is the issue of leadership. Resolving the latter requires members to take up their roles and personal authority by acknowledging that effective leadership requires active followership (Obholzer, 2001), while at the same time appreciating the concept of interdependence (Carr, 2001). Personal authority is a function of managing oneself in relation to role and task performance (Miller, 1993).

The use of defence mechanisms to deal with difficult experiences and emotions that are too threatening or too painful to acknowledge can be seen in task or work groups (Halton, 1994). Denial or avoidance is used to repress thoughts, feelings and experiences that cause anxiety, and envy results in cases where the group sees itself as the loser in a competitive situation. Regression to the paranoid-schizoid position is common with members of a group splitting off bad internal behaviours as well as conflicting needs and emotions and projecting these onto another individual, group or organisation. Projective identification implies that the recipients of a projection react to it in such a way that their own feelings are affected. Levy (2008) illustrates the extreme of this process: collective anxieties cause the individual to act against the self and on behalf of the large group. By projecting outside of the group, the natural boundary between insiders and outsiders is exploited (Halton, 1994) and it blurs the boundary between what is inside the group and what is in the environment, thus distorting reality (Moylan, 1994). A shift from the paranoid-schizoid position to the depressive position takes place when members of the group are able to tolerate previously unbearable feelings long enough to reflect on them, thus causing them to reown those feelings and bringing about a decrease in splitting (Erlich, 2001; Halton, 1994).

The extension of these dynamics to an organisational level is explained in terms of the formation of social defence mechanisms (De Board, 1978; Stokes, 1994). Individuals and groups in an organisation externalise aspects of themselves that cause anxiety and the structure of an organisation is thus to some extent formed and modified by the defence mechanisms of individuals and groups. Hence the organisation contains anxieties (relating to the task and to interpersonal relationships) and serves as a defence mechanism or social defence system - a container for individual anxieties (Czander, 1993; De Board, 1978; Obholzer, 2001; Stokes, 1994). These defences are necessary for coping with stress, but could also obstruct contact with reality and prevent the organisation from fulfilling its task and adapting to changing circumstances (French \& Vince, 1999). The changes in structural features that occur during organisational transition furthermore imply that the familiar social defence system is no longer functional and appropriate containment is needed until a new system has been established (Krantz, 2001). On a broader level, organisations, especially public institutions, also serve as containers for social anxieties (De Board, 1978; Obholzer, 1994b; Stokes, 1994).

The open systems perspective provides for an understanding of the individual, the group and the organisation as open systems involved in continuous transactions with an environment (Miller, 1993; Miller \& Rice, 1967, 1975, 1990). Systems psychodynamics refers to the interaction between the structural features of the organisation with its members, which stimulates patterns of individual and group dynamic processes. These processes, in turn, result in the organisation's culture, role definitions, boundary definitions and the management and regulation of these roles and boundaries (Czander, 1993; De Board, 1978; Stokes, 1994). Boundaries exist to contain anxiety (Cilliers, 2000; Cilliers \& Koortzen, 2000), but transactions relating to the organisation's task occur across the boundaries between systems. A study by Bar-Lev Elieli (2001) illustrates the necessity for continuous interchange with the environment (materials, people, information, ideas, values or fantasies) for existence and survival. Members of the different subsystems have to realise that the transition involves the whole system; interaction with the organisation and the outside environment is essential to ensure the success of their own transition.

The concept of group relations training, as explained by Rice $(1965,1975)$ amongst others, with its focus on interpersonal, intergroup and institutional relationships, is often used in organisational consultation, including contexts of change (e.g. Miller, 1993). This implies psychoanalytic consultation which, through interpretation and insight, leads to structural change in terms of the psychic structure of the organisation. Aspects of the system addressed during such a consultation are boundary maintenance and regulation, task analysis, authority and leadership, role definition, interorganisational relations and subsystem dependency and autonomy (Czander, 1993). Interventions are customised for the organisation and usually consist of different stages involving different individuals and groups representing the management and staff. Various studies illustrate the different methods and tools utilised, such as climate surveys, individual and group interviews and teambuilding sessions (Bar-Lev Elieli, 2001; Cilliers, 2000; Haslebo, 2000; Neumann, 1997; Nielson, 2000; Stapley, 2001). The active role of the consultant in this process is emphasised (Cilliers, 2000). The consultant attends to group members, the self and coconsultants as well as to how the group functioning relates to parallel processes in the consultancy team (James \& Broussine, 2007). Boundaries of task, time and space are also noted. Through the creation of greater awareness, a psychodynamic intervention facilitates the change in a group required for transition at an organisational level (Cilliers, 2000). Systemic relationships imply looking at the group, the organisation and the environment (Miller, 1999) and the consultant has to understand the organisational culture and not work against it when effecting change.

In line with the psychodynamic approach, the present study focused on relationships in the management team as well as the relationships between the team and other related systems. The aim was to identify operational and behavioural issues in the management team, the plant and the company and formulate hypotheses on the processes and dynamics in the various systems. Not only did the study provide the management team with insight in terms of their reaction to the change process but it also illustrated the complexity of the interaction between, and mutual influence of, the various systems during this process. At a broader level, the study contributes to the understanding of the application of the theory on the systems psychodynamic approach as well as suggesting the use of a methodology. Recommendations for an intervention of this nature were also based on the study. 
The section below on the research design includes a description of the research participants and a discussion of the data collection methods, which comprised semi-structured one-toone and group interviews and observation during a day-long group consultation. An explanation is given of the use thematic analysis to identify operational and behavioural issues and formulate hypotheses on the processes and dynamics in the various systems. The findings of the different stages of data gathering are presented, followed by a discussion of the concluding hypotheses. These hypotheses are presented as broad thematic categories and relevant literature is used as interpretive framework. The article concludes with an evaluation of the impact of the perceived dynamics on the ability of the various systems to deal effectively with the process of change.

\section{RESEARCH DESIGN}

\section{Research approach}

The theoretical paradigm of the study was interpretive (Terre Blanche \& Durrheim, 1999; Terre Blanche \& Kelly, 1999). This paradigm suggests an emphasis on the contribution of human subjectivity to knowledge without sacrificing the objectivity of knowledge - in other words, understanding subjective meaning objectively. The systems psychodynamic perspective based on the theory and concepts of psychoanalysis, group relations and open systems theory (Gould, 2001) was used to study a management team and its relationship with other systems in and outside the organisation. The research domain consisted of the internal reality and subjective experience of participants and the goal was to understand and describe this reality (Mouton, 2002; Mouton \& Marais, 1996). To ensure that this understanding is reliable and valid, the researcher had to be emphatic and had to practise observer intersubjectivity.

\section{Research strategy}

The study can be defined as an interpretive case study (Stake, 2000) with a focus on understanding and describing the functioning of a management team in a specific organisation with due consideration of the role of related systems in a context of change. Although theory provided an explanatory framework, the aim of the study was not to test formal hypotheses but instead to be flexible and allow a systematic explanation of the interrelatedness of the concepts to emerge through rich descriptions of the data. Triangulation was applied, making use of a variety of data sources and different techniques of data collection (Janesick, 2000; Kelly, 1999).

\section{Research method}

\section{Research setting}

The study was conducted at a plant of a South African production company. Corporate management expressed dissatisfaction with production (measured in terms of outputs and losses) at the plant and an intervention focused on the management team was requested. Continuous change in technology and customer demands necessitated changes both at an operational level and in terms of personnel needs. It was suggested that the codependence between the various systems in the environment required a systemic approach to studying change and its effect. The staff, the management team, corporate management, the suppliers and the customers, as well as the community and even the broader society, were all regarded as influencing each other. A product-centred orientation to change management would not have been inappropriate in this environment but customer centricity also requires acknowledging the role of individuals, intra-organisational dynamics and the broader context (Desai, 2008).

\section{Entrée and establishing researcher roles}

The intervention was requested by corporate management and access to the plant was managed by the general manager.
The other participants were therefore not informed in terms of the overall process and its aims. All participants, however, were involved in discussions on aspects of the process and its progression as these related to them. Each action was to some extent voluntary and was implemented with due consideration of the impact on a participant or participants. The study was evaluated in terms of ethics and especially the potential impact on participants was monitored in terms of the guidelines set by an ethical committee. Participants were furthermore ensured that all information would be treated as confidential. The individual consultants were involved to a greater or lesser extent during the different stages of the intervention, while the researcher/author was involved throughout.

\section{Participants}

The context provided an opportunity to study the effect of organisational change from a systems psychodynamic perspective. This implied pre-selection in terms of the company, the plant and to an extent certain role players. As such it can be regarded as a convenience sample. Respondents included the director of manufacturing, the director of human resources, the general manager, an 11-member management team and staff representatives. The directors and the members of the management team were primarily White males and the number of years with the company varied from a few years to more than 10 years. The representatives of the technical staff were also primarily White males, whereas the representatives of the workers were primarily Black males. To ensure confidentiality, the details of the primary task of the company and biographical data on individual respondents cannot be provided.

\section{Data collection methods}

Semi-structured, one-to-one interviews with the directors were aimed at obtaining background information in order to form a general impression of the context and identify behavioural and operational issues at the plant. Ideas were furthermore formed on the processes and dynamics in the different systems. The information obtained was used to guide individual interviews with the members of the management team aimed at further exploring the issues identified. Individual interviews allowed not only for an impression of the research context but also for individual experiences of this context (Terre Blanche \& Kelly, 1999).

Themes and subthemes that had emerged at this stage were presented for discussion during group interviews held with the management team and a group consisting of representatives from all levels (i.e. management and staff). The aim was to obtain feedback on the preliminary interpretations. Although group interviews are structured in terms of task, the goal is still to understand participants' thinking on experiences. Individual experiences as well as the processes and dynamics of the group as a whole are explored (Terre Blanche \& Kelly, 1999).

Observation during a day-long group consultation session with the management team was the primary source of information on the processes and dynamics, in this team in particular, but also in related systems. Time, role and task boundaries were stated at the beginning of the session but the session itself was unstructured. The consultants analysed the relatedness in the team and with other subsystems in the organisation (Gould, 2001). This involved the selective interpretation of and feedback on covert and dynamic aspects of the systems in the organisation (Haslebo \& Nielson, 2000).

\section{Recording and analysis of data}

Detailed notes, including reflective notes on personal experiences, were kept and transcribed as a description of what happened and what was said during the interviews. A degree of interpretation took place in the recording and typing of the data. However, this was not seen as problematic because qualitative 
research includes an inseparable relationship between data collection and data analysis (De Vos, 2002). Content analysis (De Vos, 2002: Janesick, 2000; Stake, 2000; Terre Blanche \& Kelly, 1999) of the data gathered during the individual interviews resulted in the identification and interpretation of themes relating to the operational and behavioural issues with regard to the management team, the plant and the company. This included formulating preliminary hypotheses on the processes and dynamics in the various systems. The group interviews provided some validation and these hypotheses were further expanded on the basis of the observations during the consultation session. A detailed description and interpretation of the consultation session specifically are provided by Van Eeden and Cilliers (2009). The preceding interpretations were integrated in concluding hypotheses informed by the systems psychodynamic approach (Cilliers \& Koortzen, 1997; Cilliers, Rothmann \& Struwig, 2004; Czander, 1993; De Board, 1978; Gould, 2001; Miller, 1993; Miller \& Rice, 1967, 1975, 1990; Stokes, 1994). Using the self as instrument in qualitative research implies that researcher subjectivity directs the data gathering and interpretation of findings. However, using various sources and techniques to obtain information enabled the researcher to verify the interpretations and explore (plausible) alternative explanations, thus contributing to the validity of the qualitative process (De Vos, 2002; Greeff, 2002). A saturation point (Johnson, 2002) was reached in terms of the information obtained and the conclusions drawn. A degree of generalisation based on these conclusions is therefore possible, but because of its contextual nature, there are limits to the transferability of the findings of an interpretive case study (Kelly, 1999).

\section{Reporting}

The findings of the different stages of data gathering are presented in the next section, followed by a discussion of the concluding hypotheses on the processes and dynamics in the management team and related systems. These hypotheses are discussed with reference to relevant literature and telling examples from the various stages of data gathering are used to strengthen the arguments.

\section{FINDINGS}

\section{Individual interviews}

Analysis of the individual interviews with the directors and the members of the management team resulted in five themes namely, the work context, the community in which the plant is situated, corporate management, the management team and the workforce and other staff. This was a production organisation in a specialised field. Safety was one of the elements of the product manufactured by the organisation and safety and security were also elements of the physical environment at the plant (the consultants observed the safety, heat and noise issues during a tour of the factory). Related to this was the fact that production was highly structured and attention to detail was important. Pressure related to an increase in customer demands, labour issues, technological advances and inadequate production was mentioned by corporate and plant management and structure probably helped to contain the resultant anxiety. The general manager and managers from the production side of the plant as well as from services saw the bottom line as 'getting things out of the door' and all staff members were measured in terms of production outcomes. Members of the management team were ambivalent in their reaction to the context - for example, problems in terms of defects (losses) versus the increase in production over the past years, the fact that the plant was no longer the flagship of the company versus the general manager's opinion that the plant would 'become the best in the group in one year', and the pressure (inter alia, in terms of the high standards expected by customers) versus the advantages implied by a wide national and international market.

The political history and the culture of the community in which the plant is situated were reflected in the reference to 'us and them'. The management culture (by implication, of the white staff) had developed over a lengthy period and these managers were referred to as 'old hands', implying expertise but also the fact that they felt threatened by and resisted change. The core of the workers (who were primarily black) had been part of the struggle and this contributed to the workforce having a uniform culture. The resultant attitudes were regarded as problematic in terms of work ethic, lack of pride in their work, discipline and a lack of understanding of business principles. Division along racial lines and different languages affected communication and the development of trust, and created a context for projection.

The managing director's autocratic leadership style was mentioned and a comment was made about the company being 'fear-driven'. To deal with the resultant pressure and fears about their own ability to meet demands, the directors also exercised control by being prescriptive. The impression that corporate management controlled the plant impacted on mutual trust and also disempowered the plant management and lowered their confidence.

It was said that the general manager was popular and that the members of the management team respected his work ethic and involvement. Caring, mutual respect and trust as well as providing staff with a vision were mentioned. However, comments by the directors and the members of the management team also indicated someone who probably reacted to pressure with efforts to maintain control (sense of responsibility, hard work, effort and long hours, attention to detail, commitment to doing things right, structured procedures in dealing with performance issues, and suggesting reasons for problems and not solutions). The general manager accepted responsibility for his management team and protected them. They were thus not authorised to take up their management roles, which resulted in dependency. The team members were also perceived as controlling and taking responsibility for the work of others. Efforts to control everything resulted in overload and more than one person referred to the resultant crisis management ('slaan vure dood' [extinguish fires]). This dynamic was furthermore reflected in the problems they had with time management (e.g. references to long hours and too many and ineffective meetings). A need was expressed by more than one manager for sharing responsibility and for inclusion of and participation by the entire team (probably also reflecting a need for safety). However, the team was not perceived as unified and references were made to boundaries between departments and the split between production and services. People management, in particular, seemed to cause anxiety, and communication and trust between management and the workforce were regarded as problematic. Projection of amongst others issues related to competence onto subordinates provided a reason for control.

Both middle and first-line management experienced role conflict (the latter in terms of their position in the community versus that in the plant). There was a perception that if the workforce and their leadership were empowered, they would assume personal responsibility and become accountable (a change in involvement and commitment was already evident). However, some doubt was also expressed as to whether all workers wanted the responsibility. Capacity building was seen as a challenge by all and various managers regarded discipline as problematic. A distinction was made between older members of the workforce and younger/newer members, with the former being regarded as less competent and with a greater lack of discipline. Teamwork was regarded as a vehicle for transformation.

\section{Group interviews}

The preliminary interpretations were further explored during the group interviews. The management team again showed insecurity associated with the changes taking place as well 
as resistance to change. Unresolved issues related to the functioning of the management team prevented them from moving forward and no vision or strategy seemed possible at this stage. The consultants' role in carrying some of the confusion could be seen in, for example, a premeeting relating to the group interview with the management team being cancelled and the consultants having difficulty in finding their way to the plant on the day of the group interview. By working through the feelings of confusion on the management team's behalf, the consultants helped the team to shift to some extent in terms of their attitude towards change. The management team furthermore created safety by trying to keep the team contained but fluctuations in the team indicated that these efforts were not completely successful. The team indicated a greater need for structure, identified as another way in which the team dealt with pressure and anxiety. The team seemed leaderless and struggled to create structure, manage their time, make decisions, deal with ambiguity, communicate constructively and resolve conflict (for example, some managers did most of the talking, comments were directed at the consultants, others' ideas were criticised and there was a split between production and services). The managers indicated that they were not authorised to take responsibility and that their subordinates did not want to accept responsibility. They referred to the pressure they were experiencing and that they reacted by going into 'panic mode' and trying to control everything. They 'pushed down' and 'forced down' accountability.

The general manager and some members of the management team attended the group interview with the broader group of representatives (possibly reflecting their need for control). The session was structured with clear time, role and task boundaries, which seemed to enable the participants to function effectively. Anxiety was furthermore contained by the representatives acting in role (e.g. the human resources manager emphasising relationships). Although there was insufficient exploration of the experiences of this group, the consultants saw them as positive and considered them to be the level at which transformation could start.

\section{Group consultation session}

Behavioural and operational issues as well as processes and dynamics, not only in the management team but also in relation to the broader context, were further explored during the group consultation session. During the preparation period both the consultants and the members of the management team showed apprehension - to be expected in an unfamiliar situation. Various factors pointed to the creation of a safe environment and maintaining the so-called family - for example, issues of inclusion, seating arrangements and the fact that the role definitions and boundaries were successfully negotiated.

A task focus and a resultant need for a clear task with related objectives were identified during the first time period. The team members, however, did not seem able to create structure but reacted to feelings of confusion and frustration by looking for help from outside the group. The general manager asked what had to be achieved while other comments included 'do not understand today's process', 'in the dark' and 'tell us'. The dependency dynamic was possibly a feature of the group's usual functioning and the general manager seemed to take up the responsibility for meeting this need by trying to find clarity and providing structure on behalf of the group. The discussion moved to the importance of talking to one another, an awareness and understanding of the self and others and how members complemented one another to the benefit of the group (without denying differences and a possible need for change). Confusion in task versus people management was reflected in the group's competitiveness ('me' rather than 'us') and the struggle with communication and interpersonal relationships. This prevented the formation of a team identity (mention was made of a split between services and production). Working in the here-and-now caused discomfort and talk returned to the task at hand.

During the second time period, the managers soon focused on process issues, such as the need for understanding and appreciation as individuals. The general manager voiced the discomfort of dealing with the here-and-now and with soft versus hard issues. Talk returned to a content-related discussion on problems such as the long work hours being blamed on their inability to delegate and manage others. Work-related frustrations were identified in terms of the workforce (e.g. incompetence, lack of skills and lack of discipline) and in terms of corporate management (e.g. absence of a plan, keeping power and lack of support). Lack of unity in, and action by, the team were partly blamed on the focus on individual interests instead of a common goal. Respect for authority was seen as culturally based and it was said that the team members struggled to challenge authority. Dependency prevailed, despite efforts from the general manager to combat this. The consultant commented that each member had to take up authority and that the accompanying anxiety had to be managed rather than using defences such as blame to deal with it.

Members continued to express their need for sufficient and open communication, sharing and mutual support in the team during the third time period. Issues of inclusion were again mentioned and it was clear that the group was still relying on containment in the team, thus reflecting their dependency issues. There was some willingness to acknowledge and show their vulnerability. However, talk returned to problematic issues related to production, indicating a shift from process to content issues. The team members' defence against anxiety resulted in antitask behaviour, such as the projection of incompetence onto the workforce. This caused even more pressure because it implied greater responsibility for the management team which, in turn, was resolved by members becoming dependent on the general manager who said that 'it takes courage to come to work'. The system did not seem to authorise leadership, but rather enforced the dynamic of control and dependency. The group explored this dynamic with references to their relationship with the general manager and to subordinates. However, it was again said that responsibility had to be 'pushed down' and people lifted up, implying 'giving' authority. Flight behaviour in the form of projection onto corporate management as the enemy also resulted.

The focus in the last time period was on how the members saw their own job and that of others. Creativity, knowledge, conscientiousness, resilience and drive, and professionalism were mentioned, but a task focus was also clear in the sense of responsibility, an emphasis on standards and a noncompromising attitude. Reference was furthermore made to a degree of passivity in dealing with pressure. The general manager indicated that he wanted to work as part of a team and that he was uncomfortable in a controlling role because of the dependency that this involved. Comments were made regarding the overload impacting on his health and although he taught his team a lot, he did not give them or expect sufficient responsibility from them. His perfectionism also had negative consequences in terms of production. He showed compassion, but some people did not experience him as supportive.

\section{DISCUSSION}

As this was an interpretive case study, the focus was not on testing hypotheses, but rather on understanding and describing the functioning of a management team and the role of related systems. In line with the aim of the study, themes relating to the operational and behavioural issues in the management team, the plant and the company were identified. Based on recurring themes, a number of comprehensive hypotheses were formulated regarding the processes and dynamics in the various systems. These hypotheses were explored from a 
theoretical perspective and support for conclusions contributed to the validity of these conclusions. The hypotheses related to the change experienced in the organisation, the overemphasis on control in the various systems, efforts to move from dependency to interdependency, personal authority as a requirement for interdependent functioning and problems with interrelatedness. Although categories were used in the discussion of the hypotheses, the processes and dynamics referred to in these categories were related. This reflects the interrelatedness between the various systems and the impact of this on the reaction of the management team and other systems to the change process, thus illustrating the application of the systems psychodynamic approach in an organisational context.

\section{A context of change}

Transformation in the organisation was necessitated by technological demands and labour-relation issues and a shift from a procedural to a participative approach was indicated. These changes are in line with global trends (Krantz, 2001). At the same time, the plant showed inadequate production (in terms of the losses reported) in an outcomes-driven environment. All the role players mentioned related pressure and were probably experiencing the insecurity (and resistance) associated with change (Krantz, 2001). During the group consultation session, one of the managers stated that he 'felt scared some mornings' In an organisation experiencing change, lack of clarity and a loss of control lead to anxiety and the accompanying dynamics (Bar-Lev Elieli, 2001). The pressure and resultant anxiety associated with the work environment, especially in a context of change, explained many of the dynamics observed in the management team. Borg and Magnetti (2004) refer to a point at which anxiety triggers typical defences. In the present context this could have occurred with the request for an intervention process.

The confusion associated with a time of change could be seen during the individual interviews in team members' fluctuation between difficulty in formulating a vision and a more optimistic outlook. Optimism was accompanied by a somewhat vague and idealistic vision of 'world-class excellence' inspired by the general manager during the group consultation session. A hopeful attitude towards the future could reflect adequate reality testing, but where the latter is somewhat diminished, an idealised conception of the changes to take place is possible (Krantz, 2001). The management team and related systems in the organisation had to be aware not only of the external reality, but also had to reflect on the internal reality, the latter requiring a state of being (as opposed to a condition of doing) (Bar-Lev Elieli, 2001). The management team indicated an awareness of the outside reality - that is, of global competition and the need for change. As seen in the ensuing discussions, some success in understanding unconscious motivations was also reached during the intervention process.

The consultants carried some of the confusion associated with the lack of clarity, thus providing a degree of containment during the transition as the organisation did not fulfil this function (James \& Huffington, 2004; Krantz, 2001). Borg and Magnetti (2004) refer to an emotional space to work through anxiety. Based on the concept of transference, consultants experience a process parallel to that in the group - group members unconsciously put their feelings onto the consultants (James \& Broussine, 2007). If the consultant is aware of his or her own experiences, possible projections and introjections are identified and he or she acts as a container until the members are ready to take back their feelings (Seel, 2001; Stapley, 1996). Borg and Magnetti (2004) vividly illustrate how they, as consultants, enacted the dynamics of the group with whom they were working and the effect it had on their own relationship.

\section{Containment through control}

The product of this organisation symbolised safety and, as such, served as a defence system on a broader level by containing and managing anxiety (De Board, 1978;Obholzer, 1994b;Stokes, 1994). At an unconscious level, organisations also contain anxiety and provide security for their members (Czander, 1993; Cilliers \& Koortzen, 2000; De Board, 1978; French \& Vince, 1999; Obholzer, 2001; Stokes, 1994). The defences provided by an organisation could help with coping, task performance and adjustment to changes. However, they could also obscure reality and prevent the organisation from fulfilling its task and adapting to change. Furthermore, an organisation experiencing change cannot offer the necessary containment, leading to anxiety and resistance to change (James \& Huffington, 2004; Krantz, 2001). Structural and procedural strategies can be implemented to offer containment during the transitional period - that is, before another defence system has been developed (or as indicated, the consultants can partly provide this function). The use of projection as a defence was noted in this instance and a reliance on control developed in reaction to the flexibility of the environment.

Control over the environment was a practical necessity, but probably also served the function of containing anxiety. The organisation's primary task was seen as production, while safety was a practical consideration that directed the production procedures. Related to this was the recurrent theme of structured procedures involving attention to detail and adherence to standards and regulations. In view of the changes that were taking place, there seemed to be excessive reliance on these procedures, standards and regulations and a culture of control was identified in the organisation. In line with the culture of control, a centralised leadership style, a lack of development of personal authority and the resultant dependency of subordinates characterised different levels of the organisation, starting with corporate management. It is possible that without change at this level, change efforts by the plant management would not be possible (see the comments by Kline, MacLeod \& McGrath, 1996, that factors external to the team hinder team performance the most; see also the reference by Coppersmith \& Grubbs, 1998, concerning the need for management to model change). Various authors (e.g. Krantz, 2001; Neumann, 1999; Obholzer, 1999; Stapley, 2001) refer to the containment role of management in a context of change. Excessive control, however, could result in a basic assumption of dependency at group level (Bion, 1961, 1975; De Board, 1978; Kets de Vries \& Miller, 1984; Rioch, 1970, 1975) and even at organisational level (Kets de Vries \& Miller, 1984; Schneider \& Shrivastava, 1988). Furthermore, perceived politics have been linked to negative emotions which, in turn, mediate the relationship of the former with attitudes and behaviours (Rosen, Harris \& Kacmar, 2009). Resistance to dealing with process issues, including emotional implications, was seen in this content-driven environment.

Characteristics that reflect a transformational leadership style were mentioned in relation to the general manager. This style has also been related to leader emotional intelligence (Schlechter \& Strauss, 2008) (note that according to Conger, 1999, identification with the leader could have played a role in the dependency dynamic referred to in the next section). Transactional elements, including a sense of responsibility, providing followers with structure and dealing with issues in a controlling manner, were also observed. The latter behaviours were appropriate to the manufacturing environment and, as Krantz (2001) indicates, structures and procedures also serve as containment in organisations undergoing change. However, the general manager seemed to overemphasise these behaviours to deal with pressure and the resultant anxiety - anxiety projected onto him by the team and the organisational system. Because of this, he was experiencing role overload and feelings of burnout, tiredness, helplessness and not being connected ('it takes courage to come to work'). Both the centralised leadership style practised by corporate management and the dependency of the management team contributed to the manager not being authorised to assume his leadership role. 
The management team also used control over both processes and people to deal with anxiety. Although some of the team members indicated behaviours associated with transformational leadership, all the members practised active transactional leadership and more passive styles of management were reflected in the use of apathy, passivity and non-involvement in dealing with pressure. The organisation was results driven and there was little tolerance for uncertainty and ambiguity. The team members indicated a task focus but nevertheless struggled to obtain clarity in terms of the primary task of the team and the plant (Miller \& Rice, 1967, 1975, 1990). This reflected energy that circulated and became stuck partly because of too much control and structure. French and Vince (1999) refer to the fact that the containing function of organisations could result in rigidity. Kruppa and Meda (2005) illustrate how efforts to create structure drained energy from group members and attributed the resultant 'stuckness' in the group to the anxiety caused by the task-process paradox. A similar dynamic was observed during the group consultation session.

In this organisation, production was regarded as the essence. A right/wrong attitude was appropriate in terms of the production process, but when applied to people it created opportunities for splitting and projection. In this instance, the management team projected onto the workforce and their leadership in seeing them as incompetent, irresponsible, dependent and in need of being controlled. Subordinates were consequently not trusted or allowed to take up their authority which, in turn, resulted in their dependency. This placed even more responsibility and pressure on the members of the management team and led to feelings of frustration, helplessness, hopelessness and anger. The team furthermore projected their own need to control onto corporate management and together with the projection of incompetence onto the workforce, this left them powerless in the middle. They were not allowed to take responsibility and their subordinates did not want to take responsibility.

\section{Dependency versus interdependence}

Instead of authorising leadership, the system seemed to be using it to fulfil dependency needs. Responsibility and accountability were advocated at all levels, but throughout, accountability was equated with 'who was to blame', justifying the need for control and resulting in a struggle for power. It is suggested that delegated authority (Obholzer, 1994a) was not exercised because of a lack of power (Carr, 2001; Czander, 1993; Miller, 1993; Obholzer, 1994a; Shapiro, 2001). This struggle was reflected in the consultants representing different levels of authority (also indicating the consultants' boundary role). Kärreman and Alvesson (2009) explain the concept of counterresistance that develops because of power dynamics. When it is difficult to exercise resistance in an organisation, resistance in itself is resisted to create a context of compliance. This could partly explain why managers did not take up their leadership role in the present context.

The general manager provided containment and a sense of safety for the management team which enabled them to work but which also implied dependency. His style made it difficult for the team members to take up their own authority. They struggled to challenge authority and expressed aggression relating to authority. At the same time, they resisted efforts to take up personal authority and seemed to be using dependency (and the resultant flight into passivity) as a way of dealing with pressure. A group working on the basic assumption of dependency obtains security and direction from one individual, in this case the general manager (Bion, 1961, 1975; De Board, 1978; Kets de Vries \& Miller, 1984; Rioch, 1970, 1975). This state is also characterised by ambivalence towards authority when counter-dependency develops. A basic assumption group acts as a closed system with inadequate acknowledgement of the external reality.
Obholzer (1994a) refers to the need for the membership to sanction the authority of the role as well as that of the person in the role. The dependency needs of the management team, however, required the general manager to be one of the team rather than functioning on the boundary as a representative of the team, the plant and corporate management (Bar-Lev Elieli, 2001). Cilliers and Koortzen (2000) refer to the manipulation of the leader out of his or her role. The boundary role as a function of leadership is essential in managing change in accordance with adjustments in the organisation's vision and primary task (Obholzer, 2001). If there is role confusion and authority boundaries are not clearly specified, the leader becomes disempowered (Cilliers, 2001; Cilliers \& Koortzen, 2000; Shapiro, 2001). The general manager resisted the dependency upon him ('ek is nie jou pa nie' [I am not your father]) but was drawn into this role.

Projective identification entails that the recipients of a projection unconsciously identify with the projected feelings and often behave accordingly (Halton, 1994). It was not clear to what extent the workforce accepted and acted upon projections of incompetence. Statements referring to incompetence and negativity reflected projections, and the workforce did not appear to always take up these projections (being a possible positive force in transition). It was possible, however, that the workers were comfortable in a position of dependency and might have resented having to take up personal authority and the consequent responsibility (reliance on being 'saved' by new workers was observed).

\section{Personal authority}

Personal authority refers to the confirmation of authority from within an individual by the individual himself or herself (Obholzer, 1994a), and implies managing oneself in relation to role and task performance (Carr, 2001; Miller, 1993; Obholzer, 1994a). In a manufacturing environment, especially in the local context, the issue of capacity building is central to empowerment. It was regularly mentioned that subordinates had to be empowered through coaching and support in a context of teamwork, thus enabling them to take up authority when appropriate and as negotiated in terms of role definitions and boundaries. However, the team again implied the control feature of their management style in referring to a balance between consideration for people and active control over task progression. This was reflected in the insufficient involvement of the workforce in the intervention despite the consultants' apparent concern in this regard. Control was even implied in the efforts to empower subordinates. It is interesting to note that Carr (2001) regards the term 'empowerment' as inappropriate because it implies giving others power instead of negotiating to develop their authority.

\section{Interrelatedness}

At a process level, the composition of the management team (a homogeneous group with long tenure in the case of some of its members) implied cohesion, especially in the earlier phases of group development. However, this composition could also have resulted in groupthink and a negative impact on performance in situations requiring innovativeness such as in a changing environment (Bottom \& Baloff, 1994; Dirks, 1999; Earley, 1999; Elron, 1997; Keck, 1997; Kim, Min \& Cha, 1999; Knight et al., 1999; McCauley, 1998; Shaw \& Barrett-Power, 1998; Sohoran, 1993; Watson, Johnson \& Merritt, 1998; West \& Anderson, 1996). At a dynamic level, a system deals with the fears associated with change by creating safety within (Bar-Lev Elieli, 2001). Obholzer (2001), among others, refers to the source of anxiety in the work environment as being related to the task itself and to the relationships with management and colleagues. The management team seemed to experience insecurity in task management, but insecurity in people management was more pronounced. They dealt with the accompanying insecurity 
by projecting their own feelings and behaviours onto other groups, thus protecting the fantasy that they as a 'family' were safe. Emphasis on the safety of the team implied that the members did not acknowledge the importance of interaction with the environment and of the boundary roles of some of its members. The team reacted to uncertainty with a need for containment, safety and support in the team. The need for an intervention questioned the assumption that there was safety in the general manager.

The team was unsuccessful in creating a safe system as evidenced in splits between the different departments and projections as well as issues of inclusion and exclusion that threatened its unity (mirrored in the division in the workforce). During the group session, reference was made to the 'kamstige team' [the so-called team]. This probably reflected the increase in interpersonal tension in groups that is experienced when organisational change causes less successful reliance on defences such as projection (Stokes, 1994). Emphasis on personal interests instead of on a group goal characterised the struggle for a team identity. Team members showed a need for understanding, acceptance and connection, but a lack of trust made it difficult to acknowledge and show vulnerability and also to respect these feelings in others. This, in turn, impacted on open communication and effective confrontation and conflict management. Mutual trust, awareness of feelings, acknowledgement and understanding of differences as well as an emphasis on sustaining relationships are required to develop team unity (Kim et al., 1999). Role clarity in the team and clarity in terms of group norms and values had to be established to improve relatedness in the team. A balance is required between team unity and interpersonal support implied by interdependence on the one hand and the lack of personal authority and accountability of dependency on the other hand (Carr, 2001). The team had to realise that concepts such as individual responsibility versus group support and individual versus group goals were not mutually exclusive (Locke \& Latham, 1992; Luft, 1984; Zajas, 1994). However, the leadership style and its impact on the group-decision making mechanisms could hinder the process because it could influence group choices in trust and reciprocity making (Song, 2006). Shared work values have been shown to be positively related to interpersonal trust, with the latter mediating the positive relationship between shared values and team member effectiveness (Chou, Wang, Wang, Huang \& Cheng, 2008). The dynamics of the present context, however, seem to result in so-called consensus on a centralised leadership style without being conducive to the development of trust and effective performance.

The struggle with relatedness was reflected in the team's interaction with the total system and in the problems experienced with people management. Racial and language differences, with their concomitant tensions, stereotypes, perceived threats and issues of belonging, impacted negatively on the communication necessary to develop trust which, in turn, enables people to work together. Working in teams allows for more effective reaction to change and complexity, thus making this more suitable in the contemporary organisational climate, which requires greater flexibility (Chou et al. 2008). However, a lack of trust and effective communication characterised the relationship between the management team and staff and explained why teamwork was not always successful despite the support voiced in this regard.

Transforming dependency (reliance on others) to the state of interdependence requires role clarity, accepting personal authority in terms of one's roles and acknowledging the relationship with the environment (Carr, 2001; Miller, 1993; Obholzer, 1994a). Each member of the management team had to accept his or her own part in the system and to manage the anxiety accompanying the authority and responsibility for this position. This relates to the third phase in Gantt and Agazarian's (2007) phases of system development. The relationship to authority and the leader and members' role in this relationship and relationships with colleagues characterise the first two phases, as illustrated in the present context. System development, however, also requires an integration phase including functional role-taking aimed at the larger-context goals. Closed boundaries limit development, and commitment to collaboration was needed at organisational level, requiring a rational distribution of authority, clear role and boundary definitions and the management and regulation of these roles and boundaries at this level (Gould, 2001). Interdependence is crucial when facing change (Bar-Lev Elieli, 2001; Miller, 1999; Stacey, 2001), and in this instance, interdependence was suggested between corporate management and the plant, between the plant and its suppliers and customers and between the management team and staff. The changes foreseen implied even greater interdependence in the organisation and between the organisation and other organisations. However, this was not acknowledged by the various role players, and effective interactions across boundaries were therefore not encouraged. Instead the different subsystems provided a context for projections which helped to deal with anxiety and thus adaptation, but which also prevented interdependent collaboration

\section{Conclusions}

Whereas an organisation usually provides defences against anxiety and thus security for its members, an organisation experiencing change cannot offer the necessary containment. It was indicated that the management team reacted to the resultant insecurity with the dynamics of control and dependency, and also created a closed system. The latter affected their ability to relate to the other systems in and outside the organisation. A centralised leadership style was not limited to the management team, but characterised different levels of the organisation. Control by corporate management and the dependency of the management team implied that the general manager was not authorised to take up his leadership role. Similarly, a projection of too much control onto corporate management and the general manager as well as a projection of incompetence onto the workforce left the management team powerless in the middle. It was not clear to what extent the workforce accepted these projections. A lack of effective interaction across the boundaries between systems impacted negatively on the development of interdependence, the latter being essential in this context of change. Some awareness in this regard was indicated by the management team but commitment to collaboration was needed at organisational level.

Despite changes in the environment and the demand for change these placed on the organisation, the defence of control was strengthened by these and it seems that individuals thus successfully resisted change. There was some sensitisation in the management team but a state of control and dependency remained in the system. Change outcomes were still defined as organisational outcomes instead of behavioural outcomes. This can be partly ascribed to the paradigm that focused on process in an environment that emphasised content, the intervention being focused on part of the system and premature closure. Shields, Gertler and Faulkner (2007) also refer to the perceived limitation of the systems psychodynamic approach to address organisational goals. The emphasis seems to be on individual rather than systemic impact, process rather than outcome and diagnosis rather than interventions.

The nature of the intervention probably did not provide sufficiently for the organisational culture in terms of dependency and the consequent need for structure (Stapley, 1996, 2001). According to Hempel and Martinsons (2009, p. 492), 'the change initiatives will evolve towards a form congruent with the prevailing values'. Gantt and Agazarian (2007) refer to the re-establishment of the norms of the organisation-as-a-whole. Structural as well as cultural issues determine the internal 
environment, but the change context also refers to factors external to the organisation. It can be assumed that the impact of the political history on change initiatives in this organisation will prevail. Formal assessment was already used in this organisation and future research could look at successfully aligning more structured individual and organisational assessment with the aims of the psychodynamic approach. Full understanding and directed change, however, are not always possible or feasible. Nevertheless, any organisational change needs to be sustained by continued monitoring of informal institutional changes (Desai, 2008) and provision should have been made for continued consultation to the management team, possibly combining the approach described here with other approaches to organisational development.

Despite the limitations in terms of the transferability of results in the case of an interpretive case study, this study contributes to the understanding of the application of the systems psychodynamic approach and also suggests a methodology to be used in research of this kind. It is clear that provision should be made for the organisational culture as well as the external environment and that consultation to all related systems and the possible need for continued consultation have to be considered. Business needs furthermore seem to imply interventions aimed at specific outcomes. Strategic objectives in the present context typically referred to change in terms of operational issues or to process variables when dealing with behavioural issues. Not only does this illustrate environment specific intervention needs, but it also implies possible resistance against a systems psychodynamic approach in outcomes-driven organisational environments.

\section{REFERENCES}

Bar-Lev Elieli, R. (2001). An organization looks at itself: Psychoanalytic and group relations perspectives on facilitating organizational transition. In L.J. Gould, L.F. Stapley \& M. Stein (Eds.), The systems psychodynamics of organizations: Integrating the group relations approach, psychoanalytic, and open systems perspectives (pp. 76-90). London: Karnac.

Bion, W.R. (1961). Experiences in groups. London: Tavistock.

Bion, W.R. (1975). Selections from: 'Experiences in groups'. In A.D. Colman \& W.H. Bexton (Eds.), Group relations reader 1 (pp. 11-20). Washington: A.K. Rice Institute.

Borg, M.B., \& Magnetti, E.A. (2004). The diva is/in the organization: Exploring personal/interpersonal/organizational dynamics and their enactment. Psychodynamic Practice, 10(2), 221-247.

Bottom, W.P., \& Baloff, N. (1994). A diagnostic model for team building with an illustrative application. Human Resource Development Quarterly, 5(4), 317-336.

Carr, W. (2001). The exercise of authority in a dependent context. In L.J. Gould, L.F. Stapley \& M. Stein (Eds.), The systems psychodynamics of organizations: Integrating the group relations approach, psychoanalytic, and open systems perspectives (pp. 45-66). London: Karnac.

Chou, L., Wang, A., Wang, T., Huang, M., \& Cheng, B. (2008). Shared work values and team member effectiveness: The mediation of trustfulness and trustworthiness. Human Relations, 61(12), 1713-1742.

Cilliers, F. (2000). Team building from a psychodynamic perspective. Journal of Industrial Psychology, 26(1), 18-23.

Cilliers, F. (2001). The role of sense of coherence in group relations training. Journal of Industrial Psychology, 27(3), 1318.

Cilliers, F., \& Koortzen, P. (1997). Reader: Course in group process consultation. Pretoria: Centre for Industrial and Organisational Psychology, University of South Africa.

Cilliers, F., \& Koortzen, P. (2000). The psychodynamic view on organizational behavior. The Industrial Organizational Psychologist, 38(2), 59-67.
Cilliers, F., Rothmann, S., \& Struwig, W.H. (2004). Transference and counter-transference in systems psychodynamic group process consultation: The consultant's experience. Journal of Industrial Psychology, 30(1), 110-119.

Conger, J.A. (1999). Charismatic and transformational leadership in organizations: An insider's perspective on these developing streams of research. Leadership Quarterly, 10(2), 145-179.

Coppersmith, L., \& Grubbs, A. (1998). Teambuilding: The whole may be less than the sum of its parts. Human Resource Professional, 11(3), 10-14.

Czander, W.M. (1993). The psychodynamics of work and organizations: Theory and application. New York: Guilford Press.

De Board, R. (1978). The psychoanalysis of organizations: A psychoanalytic approach to behaviour in groups and organizations. London: Routledge.

Desai, D. (2008). Role of a context and intra-organizational dynamics in customer relationship management change. International Journal of Business Insights and Transformation, 1(1), 1-9.

De Vos, A.S. (2002). Qualitative data analysis and interpretation. In A.S. de Vos, H. Strydom, C.B. Fouché \& C.S.L. Delport (Eds.), Research at grass roots: For the social sciences and human service professions (2nd edn.) (pp. 339-355). Pretoria: Van Schaik.

Dirks, K.T. (1999). The effects of interpersonal trust on work group performance. Journal of Applied Psychology, 84(3), 445-455.

Earley, P.C. (1999). Playing follow the leader: Status-determining traits in relation to collective efficacy across cultures. Organizational Behavior and Human Decision Processes, 80(3), 192-212.

Elron, E. (1997). Top management teams within multinational corporations: Effects of cultural heterogeneity. Leadership Quarterly, 8(4), 393-412.

Erlich, H.S. (2001). Enemies within and without: Paranoia and regression in groups and organizations. In L.J. Gould, L.F. Stapley \& M. Stein (Eds.), The systems psychodynamics of organizations: Integrating the group relations approach, psychoanalytic, and open systems perspectives (pp. 115-131). London: Karnac.

French, R., \& Vince, R. (1999). Learning, managing, and organizing: The continuing contribution of group relations to management and organization. In R. French \& R. Vince (Eds.), Group relations, management, and organization (pp. 3-19). New York: Oxford University Press.

Gantt, S.P., \& Agazarian, Y.M. (2007). Phases of system development in organizational work groups: The systemscentred approach for intervening in context. Organisational and Social Dynamics, 7(2), 253-291.

Gordon-Brown, C., \& Bendixen, M. (2002). Grant Thornton Feinstein Pretoria: A winning culture? (Report WBS-2002-2). Johannesburg: Wits Business School.

Gould, L.J. (2001). Introduction. In L.J. Gould, L.F. Stapley \& M. Stein (Eds.), The systems psychodynamics of organizations: Integrating the group relations approach, psychoanalytic, and open systems perspectives (pp. 1-15). London: Karnac.

Greeff, M. (2002). Information collection: Interviewing. In A.S. de Vos, H. Strydom, C.B. Fouché \& C.S.L. Delport (Eds.), Research at grass roots: For the social sciences and human service professions (2nd edn.) (pp. 291-320). Pretoria: Van Schaik.

Halton, W. (1994). Some unconscious aspects of organizational life: Contributions from psychoanalysis. In A. Obholzer \& V.Z. Roberts (Eds.), The unconscious at work: Individual and organizational stress in the human services (pp. 11-18). London: Routledge.

Haslebo, G. (2000). Organizational consultation and learning. In G. Haslebo \& K.S. Nielson (Eds.), Systems and meaning: Consulting in organizations (pp. 17-38). London: Karnac.

Haslebo, G., \& Nielson, K.S. (2000). Key concepts in systemic thinking. In G. Haslebo \& K.S. Nielson (Eds.), Systems and meaning: Consulting in organizations (pp. 101-138). London: Karnac. 
Hempel, P.S., \& Martinsons, M.G. (2009). Developing international organizational change theory using cases from China. Human Relations, 62(4), 459-499.

Horwitz, F.M., Kamoche, K., \& Chew, I.K.H. (2002). Looking East: Diffusing high performance work practices in the southern Afro-Asian context. The International Journal of Human Resource Management, 13(7), 1019-1041.

James, J., \& Broussine, M. (2007). A reflexive action inquiry into the experience of working together as consultants. Organisational and Social Dynamics, 7(2), 292312.

James, K., \& Huffington, C. (2004). Containment of anxiety in organizational change: A case example of changing organizational boundaries. Organisational and Social Dynamics, 4(2), 212-233.

Janesick, V.J. (2000). The choreography of qualitative research design: Minuets, improvisations, and crystallization. In N.K. Denzin \& Y.S. Lincoln (Eds.), Handbook of qualitative research (2nd edn.) (pp. 379-399). Thousand Oaks: Sage.

Johnson, J.M. (2002). In-depth interviewing. In J.F. Gubrium \& J.A. Holstein (Eds.), Handbook of interview research: Context and method (pp. 103-119). Thousand Oaks: Sage.

Kärreman, D., \& Alvesson, M. (2009). Resisting resistance: Counter-resistance, consent and compliance in a consultancy firm. Human Relations, 62(8), 1115-1144.

Keck, S.L. (1997). Top management team structure: Differential effects by environmental context. Organization Science, 8(2), 143-156.

Kelly, K. (1999). Calling it a day: Reaching conclusions in qualitative research. In M. Terre Blanche \& K. Durrheim (Eds.), Research in practice: Applied methods for the social sciences (pp. 421-437). Cape Town: University of Cape Town Press.

Kets de Vries, M.F.R., \& Miller, D. (1984). Group fantasies and organizational functioning. Human Relations, 37(2), 111134.

Kim, Y., Min, B., \& Cha, J. (1999). The roles of R\&D team leaders in Korea: A contingent approach. RED Management, 29(2), 153-165.

Klein, M. (1959). Our adult world and its roots in infancy. Human Relations, 12, 291-303.

Klein, M. (1985). Our adult world and its roots in infancy. In A.D. Colman \& M.H. Geller (Eds.), Group relations reader 2 (pp. 5-19). Washington: A.K. Rice Institute.

Kline, T.J.B., MacLeod, M., \& McGrath, J. (1996). Team effectiveness: Contributors and hindrances. Human Systems Management, 15(3), 183-186.

Knight, D., Pearce, C.L., Smith, K.G., Olian, J.D., Sims, H.P., Smith, K.A. et al. (1999). Top management team diversity, group process, and strategic consensus. Strategic Management Journal, 20, 445-465.

Krantz, J. (2001). Dilemmas of organizational change: A systems psychodynamic perspective. In L.J. Gould, L.F. Stapley \& M. Stein (Eds.), The systems psychodynamics of organizations: Integrating the group relations approach, psychoanalytic and open systems perspectives (pp. 133-156). London: Karnac.

Kruppa, R., \& Meda, A.K. (2005). Group dynamics in the formation of a PhD cohort: A reflection in experiencing while learning organizational development theory. Organization Development Journal, 23(1), 56-67.

Lawrence, W.G., Bain, A. \& Gould, L. (1996). The fifth basic assumption. Free Associations, 6(37), 28-55.

Levy, J. (2008). 'Nothing is performed in isolation': The individual and the group in Forster's A passage to India. Organisational and Social Dynamics, 8(2), 216-233.

Locke, E.A., \& Latham, G.P. (1992). Comments on McLeod, Liker, and Lobel. Journal of Applied Behavioral Science, 28(1), $42-45$.

Luft, J. (1984). An introduction to group dynamics (3rd edn.). Palo Alto: Mayfield.

McCauley, C. (1998). Group dynamics in Janis's theory of groupthink: Backward and forward. Organizational Behavior and Human Decision Processes, 73(2/3), 142162 .
Miller, E. (1993). From dependency to autonomy: Studies in organization and change. London: Free Association Books.

Miller, E.J. (1999). Open systems revisited: A proposition about development and change. In W.G. Lawrence (Ed.), Exploring individual and organizational boundaries: A Tavistock open systems approach (pp. 217-233). London: Karnac.

Miller, E.J., \& Rice, A.K. (1967). Systems of organization: Task and sentient systems and their boundary controls. London: Tavistock.

Miller, E.J., \& Rice, A.K. (1975). Selections from: 'Systems of organization'. In A.D. Colman \& W.H. Bexton (Eds.), Group relations reader 1 (pp. 43-68). Washington: A.K. Rice Institute.

Miller, E.J., \& Rice, A.K. (1990). Task and sentient systems and their boundary controls. In E. Trist \& H. Murray (Eds.), The social engagement of social science: A Tavistock anthology, Vol. I: The socio-psychological perspective (pp. 259-271). Baltimore: University of Pennsylvania Press.

Mouton, J. (2002). Understanding social research (3rd impression). Cape Town: Van Schaik.

Mouton, J., \& Marais, H.C. (1996). Basic concepts in the methodology of the social sciences. (Rev. edn.). Pretoria: Human Sciences Research Council.

Moylan, D. (1994). The dangers of contagion: Projective identification processes in institutions. In A. Obholzer \& V.Z. Roberts (Eds.), The unconscious at work: Individual and organizational stress in the human services (pp. 51-59). London: Routledge.

Neumann, J.E. (1997). Negotiating entry and contracting. In J.E. Neumann, K. Kellner, \& A. Dawson-Shepherd (Eds.), Developing organisational consultancy (pp. 7-31). London: Routledge.

Neumann, J.E. (1999). Systems psychodynamics in service of political organizational change. In R. French \& R. Vince (Eds.), Group relations, management, and organization (pp. 54-69). New York: Oxford University Press.

Nielson, K.S. (2000). 'Assess our manager and expose his shortcomings': A consultation in a private company. In G. Haslebo \& K.S. Nielson(Eds.), Systems and meaning: Consulting in organizations (pp. 39-71). London: Karnac.

Obholzer, A. (1994a). Authority, power and leadership: Contributions from group relations training. In A. Obholzer \& V.Z. Roberts (Eds.), The unconscious at work: Individual and organizational stress in the human services (pp. 39-47). London: Routledge.

Obholzer, A. (1994b). Managing social anxieties in public sector organizations. In A. Obholzer \& V.Z. Roberts (Eds.), The unconscious at work: Individual and organizational stress in the human services (pp. 169-178). London: Routledge.

Obholzer, A. (1999). Managing the unconscious at work. In R. French \& R. Vince (Eds.), Group relations, management, and organization (pp. 87-97). New York: Oxford University Press.

Obholzer, A. (2001). The leader, the unconscious, and the management of the organisation. In L.J. Gould, L.F. Stapley \& M. Stein (Eds.), The systems psychodynamics of organizations: Integrating the group relations approach, psychoanalytic, and open systems perspectives (pp. 197-216). London: Karnac.

Rice, A.K. (1965). Learning for leadership: Inter-personal and intergroup relations. London: Tavistock.

Rice, A.K. (1975). Selections from 'Learning for leadership'. In A.D. Colman \& W.H. Bexton (Eds.), Group relations reader 1 (pp.71-158). Washington: A.K. Rice Institute.

Rioch, M.J. (1970). The work of Wilfred Bion on groups. Psychiatry, 33(1), 56-66.

Rioch, M.J. (1975). The work of Wilfred Bion on groups. In A.D. Colman \& W.H. Bexton (Eds.), Group relations reader 1 (pp. 21-33). Washington: A.K. Rice Institute. 
Rosen, C.C., Harris, K.J., \& Kacmar, K.M. (2009). The emotional implications of organizational politics: A process model. Human Relations, 62(1), 27-57.

Rosenzweig, P. (1998). Managing the new global workforce: Fostering diversity, forging consistency. European Management Journal, 16(6), 644-652.

Schlechter, A.F., \& Strauss, J.J. (2008) Leader emotional intelligence, transformational leadership, trust and team commitment: Testing a model within a team context. South African Journal of Industrial Psychology, 34(1), 4253.

Schneider, S.C., \& Shrivastava, P. (1988). Basic assumptions themes in organizations. Human Relations, 41(7), 493515.

Seel, R. (2001). Anxiety and incompetence in the large group: A psychodynamic perspective. Journal of Organizational Change, 14(5), 493-503.

Shapiro, E.R. (2001) Institutional learning as chief executive. In L.J. Gould, L.F. Stapley \& M. Stein (Eds.), The systems psychodynamics of organizations: Integrating the group relations approach, psychoanalytic, and open systems perspectives (pp. 175-195). London: Karnac.

Shaw, J.B., \& BarrettPower, E. (1998). The effects of diversity on small work group processes and performance. Human Relations, 51(10), 1307-1325.

Shields, L.R., Gertler, B., \& Faulkner, F. (2007). Exploring the contributions of a systems-psychodynamic approach to working in organizations: An inquiry into the learning of the White Organization Program. Organisational and Social Dynamics, 7(1), 111-130.

Sohoran, E.G. (1993). Work teams demonstrate diverse advantages. Training and Development, 47(10), 9.

Song, F. (2006). Trust and reciprocity in inter-individual versus inter-group interactions: The effects of social influence, group dynamics, and perspective biases. Experimental Economics, 9(2), 179-180.

Stacey, R. (2001). Complexity at the 'Edge' of the basicassumption group. In L.J. Gould, L.F. Stapley \& M. Stein (Eds.), The systems psychodynamics of organizations: Integrating the group relations approach, psychoanalytic, and open systems perspectives (pp. 91-114). London: Karnac.

Stake, R.E. (2000). Case studies. In N.K. Denzin \& Y.S. Lincoln (Eds.), Handbook of qualitative research (2nd edn.) (pp. 435454). Thousand Oaks: Sage.
Stapley, L.F. (1996). The personality of the organisation: A psychodynamic explanation of culture and change. London: Free Association Books.

Stapley, L.F. (2001). A large-system intervention: The influence of organisational culture. In L.J. Gould, L.F. Stapley \& M. Stein (Eds.), The systems psychodynamics of organizations: Integrating the group relations approach, psychoanalytic, and open systems perspectives (pp. 157-173). London: Karnac.

Stokes, J. (1994). Institutional chaos and personal stress. In A. Obholzer \& V.Z. Roberts (Eds.), The unconscious at work: Individual and organizational stress in the human services (pp. 122-128). London: Routledge.

Terre Blanche, M., \& Durrheim, K. (1999). Histories of the present: Social science research in context. In M. Terre Blanche \& K. Durrheim (Eds.), Research in practice: Applied methods for the social sciences (pp. 1-16). Cape Town: University of Cape Town Press.

Terre Blanche, M., \& Kelly, K. (1999). Interpretive methods. In M. Terre Blanche \& K. Durrheim (Eds.), Research in practice: Applied methods for the social sciences (pp. 123-146). Cape Town: University of Cape Town Press.

Turquet, P.M. (1974). Leadership: The individual and the group. In G.S. Gibbard, J.J. Hartman \& R.D. Mann (Eds.), Analysis of groups: Contributions to theory, research, and practice (pp. 349-371). San Francisco: Jossey-Bass.

Van der Colff, L. (2003). Leadership lessons from the African tree. Management Decision, 41(3), 257-261.

Van Eeden, R., \& Cilliers, F. (2009). Social defense structures in organizations: How a lack of authorization keeps managers from moving to transformational leadership. International Journal of Organization Theory and Behavior, 12(3), 475501.

Watson, W.E., Johnson, L., \& Merritt, D. (1998). Team orientation, selforientation and diversity in task groups: Their connection to team performance over time. Group and Organization Management, 23(2), 161-188.

West, M.A., \& Anderson, N.R. (1996). Innovation in top management teams. Journal of Applied Psychology, 81(6), 680-693.

Zajas, J. (1994). A group process assessment for interpersonal growth, communications and managerial development. International Journal of Management, 11(3), 773777. 